\title{
Acoustic Neuroma Microsurgery: An Overview of the Three Main Surgical Approaches
}

\author{
Aloysio Augusto Tahan De Campos Netto ${ }^{1 *}$ Alexandre Meluzzi ${ }^{2}$, Márcia Norikode Oliveira Homa ${ }^{2}$ and Maria $^{2}$ \\ Stella Arantes Amaral ${ }^{3}$ \\ ${ }^{1}$ Department of Neurotologic Skull Base Surgery - Instituto Paulista de Otologia Ltda., São Paulo, Brazil \\ ${ }^{2}$ Department of Neurosurgery. Neuromin São Paulo-SP. Brazil \\ ${ }^{3}$ Department of Otolaryngology - Head and Neck Surgery, School of Medicine of Ribeirão Preto - University of São Paulo, Brazil
}

Submission: November 01, 2017; Published: November 27, 2017

*Corresponding author: Aloysio Augusto Tahan De Campos Netto, Otolaryngologist, Department of Neurotologic Skull Base Surgery - Institute of Paulista de Otology Ltda. Rua Cincinato Braga, 59. Cj. 1-D3. Bela Vista. Zip code: 01333-010. São Paulo-SP. Brazil, Email: aloysioaugusto@uol.com.br

\begin{abstract}
Acoustic neuromas account for the great majority of cerebellopontine angle neoplasms. The gold standard treatment option remains surgical total tumor extirpation. The aim of this article is to describe and give an overview of the three main surgical approaches for acoustic neuroma removal. The translabyrinthine, retrosigmoid and middle cranial fossa approaches and their expansions and adaptations are the three most used craniotomies for acoustic neuroma removal and represent different pathways to the skull base and cerebellopontine angle. The advantages and disadvantages of each of them and their main surgical steps are described by the authors. The treatment options and the most suitable surgical approach to use in each case shall be a very careful discussion between the patient and his physician.
\end{abstract}

Keywords: Acoustic neuroma, Vestibular schwannoma, Translabyrinthine, Retrosigmoid, Middle cranial fossa

\section{Introduction}

Acoustic neuromas (AN), also called vestibular schwannomas, are benign neoplasm's that account for the vast majority of cerebellopontine angle (CPA) tumors, followed by meningiomas of the CPA and other benign lesions occurring in this site [1]. The treatment options are microsurgery (total or subtotal), radiotherapy, radiosurgery and observation (watch and scan), depending on the tumor size, site and growth rate, patient's situation and agreement of patient and physician of the pros and cons of each sort of therapy. To the best of the authors' knowledge, total surgical removal remains the gold standard treatment option and the top priorities are, in order of importance: patient's life maintenance, preservation of facial nerve function and hearing preservation on the ipsilateral ear.

The three main surgical pathways for surgical extirpation of AS are: the translabyrinthine (translab), the retro sigmoid and the middle cranial fossa approaches. There other approaches, such as retro labyrinthine, transonic, transcochlear that are adaptations or extensions of the translabyrinthine craniotomy and can be indicated according to tumor site and size or hearing status of the injured ear. The goal of this review is to give an overview of the three main surgical approaches for a removal, describing their indications, pros, cons and principal surgical steps of each technique.

\section{The Translabyrinthine Approach}

The translaband enlarged translabcraniotomiesare lateral skull base approaches used to reach the internal auditory canal (IAC) and (CPA) regions. They offer a good exposure of the structures of those sites, such as the facial, cochlear and vestibular nerves; posterior fossa dura; lateral venous sinus (sigmoid sinus); middle fossa dura; brainstem; superior petrous sinus and jugular bulb. Using the enlarged translab approach, its modifications and the modern skull base surgical techniques, one can remove any size of (AN). The enlarged translab approach is preferred in cases of larger tumors extending to either jugular foramen or middle fossa whereas the indications of the classical translab approach should be limited to smaller tumors and vestibular neurectomy [2]. The main disadvantage of this approach is that the hearing of the injured earis sacrificed. Surgical steps of the translabapproach:
a) Patient positioning
b) Insert the electrodes for facial nerve monitoring
c) Post auricular skin incision
d) Elevation of the musculoperiosteal flap and exposure of the mastoid region

e) Mastoidectomy and skeletonization of the of the sigmoid 


\section{Global Journal of Otolaryngology}

sinus, middle fossa dura and posterior fossa dura

f) Posterior and middle fossa dura exposure, being very careful not to hit the superior petrous sinus in order to avoid a massive bleeding

g) Labyrinthectomy

h) Gentle skeletonization of IAC dura and exposure of its dura

i) Dural incision

j) Identification of the facial nerve in the IAC

k) Tumor debulk

l) Gentle dissection of the tumor in order to avoid facial nerve manipulation

m) Local hemostasis

n) Obliteration of the Eustachian tube and packing the middle ear through the facial recess with pieces of muscle

o) Obliteration of the temporal bone cavity and dural defect with strips of abdominal fat. Use bone wax to obliterate mastoid air cells to avoid postoperative cerebrospinal fluid (CSF) leakage[1].

p) Musculoperiosteallayer and skin incisionclosure

q) Dressing (Figures 1-5).
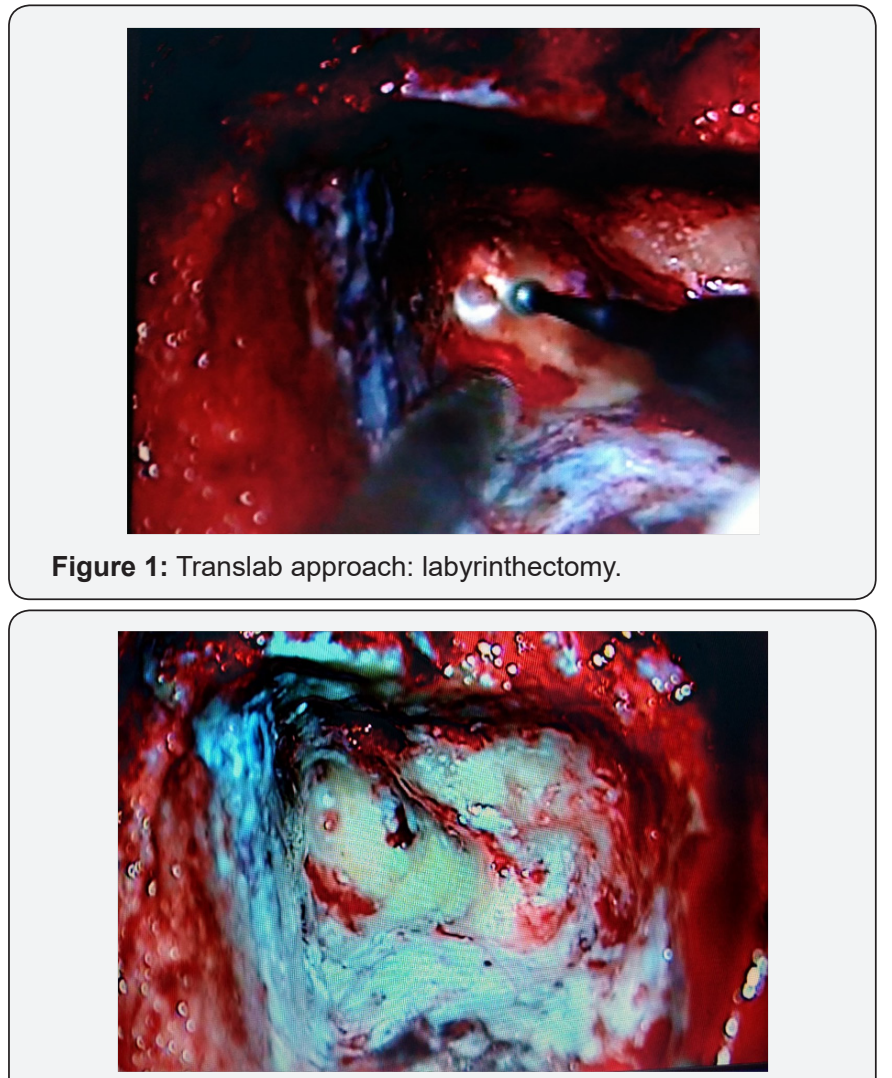

Figure 2: Bone from the IAC, middle and posterior fossa dura have been removed.

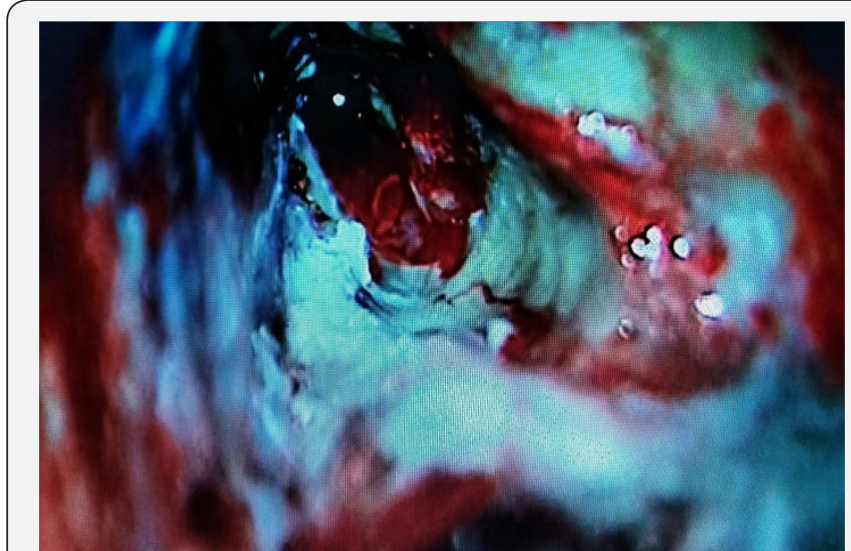

Figure 3: Tumor (AN) exposed after incision of the dura of the IAC and posterior fossa dura.

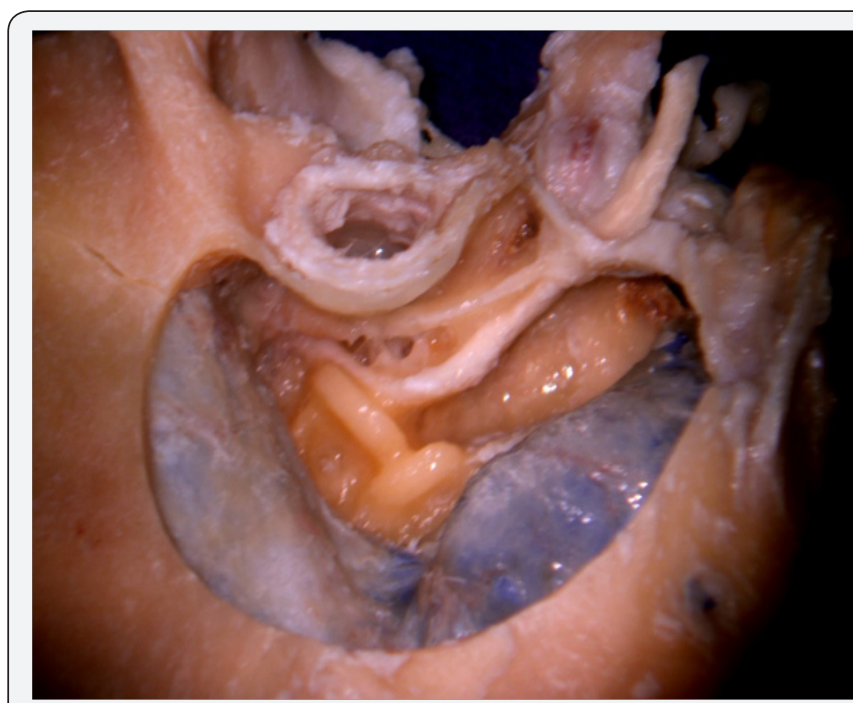

Figure 4: Cadaveric dissection-translab approach. Note the facial nerve, facial recess, chorda tympani nerve, the labyrinth, posterior and middle fossa dura skeletonized.

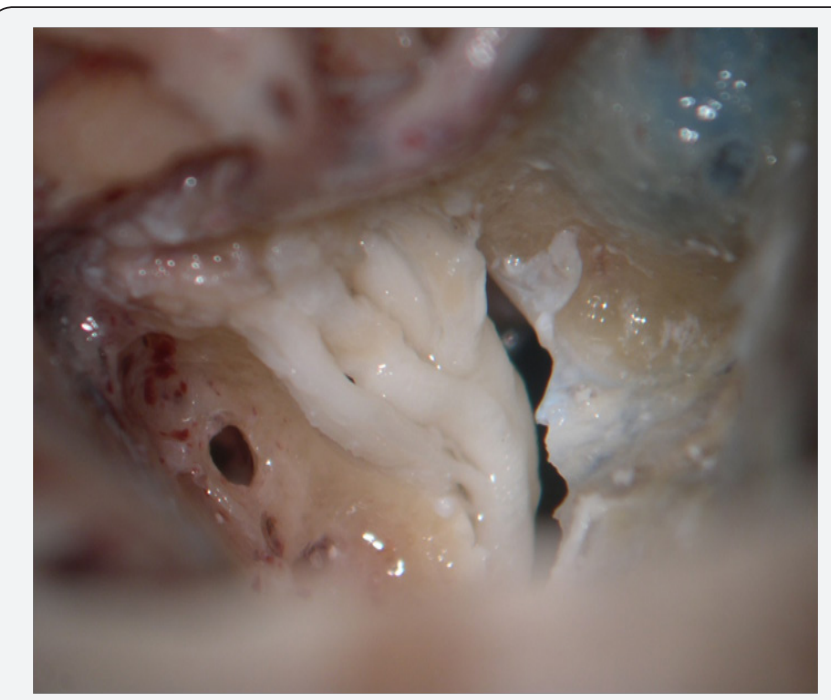

Figure 5: Cadaveric dissection - The IAC nerves have been exposed. The jugular bulb can be seen on the right and superiorly. 


\section{Global Journal of Otolaryngology}

\section{The Middle Cranial Fossa Approach}

This approach is not used as frequently as the traditional translabyrinthine and retro sigmoid approaches for accessing ANs [3].

\section{The Retro sigmoid Approach}

The retro sigmoid and the enlarged retro sigmoid approaches are also performed to respect ANs. They both give access to the CPA region and posterior fossa. The enlarged retro sigmoid approach includes the skeletonization of the transverse-sigmoid sinus and an optional posterior mastoidectomy to expose the jugular bulb [4]. Retro sigmoid craniotomies are indicated most commonly for CPA tumors (with mostly cisternal component and serviceable or residual hearing), lateral cerebellar, petrous face or lateral lesions up to Meckel's cave, auditory brainstem implantation, vestibular neurectomy and micro vascular decompression [5]. Using the retro sigmoid approach, as in the enlarged translab approach, the surgeon can reset any size of acoustic neuroma, despite the major difficulty to reach the more lateral part of the IAC (the fundus of the IAC) and remove tumor in this area (Figures 6 \& 7). Main surgical steps of the retro sigmoid approach:

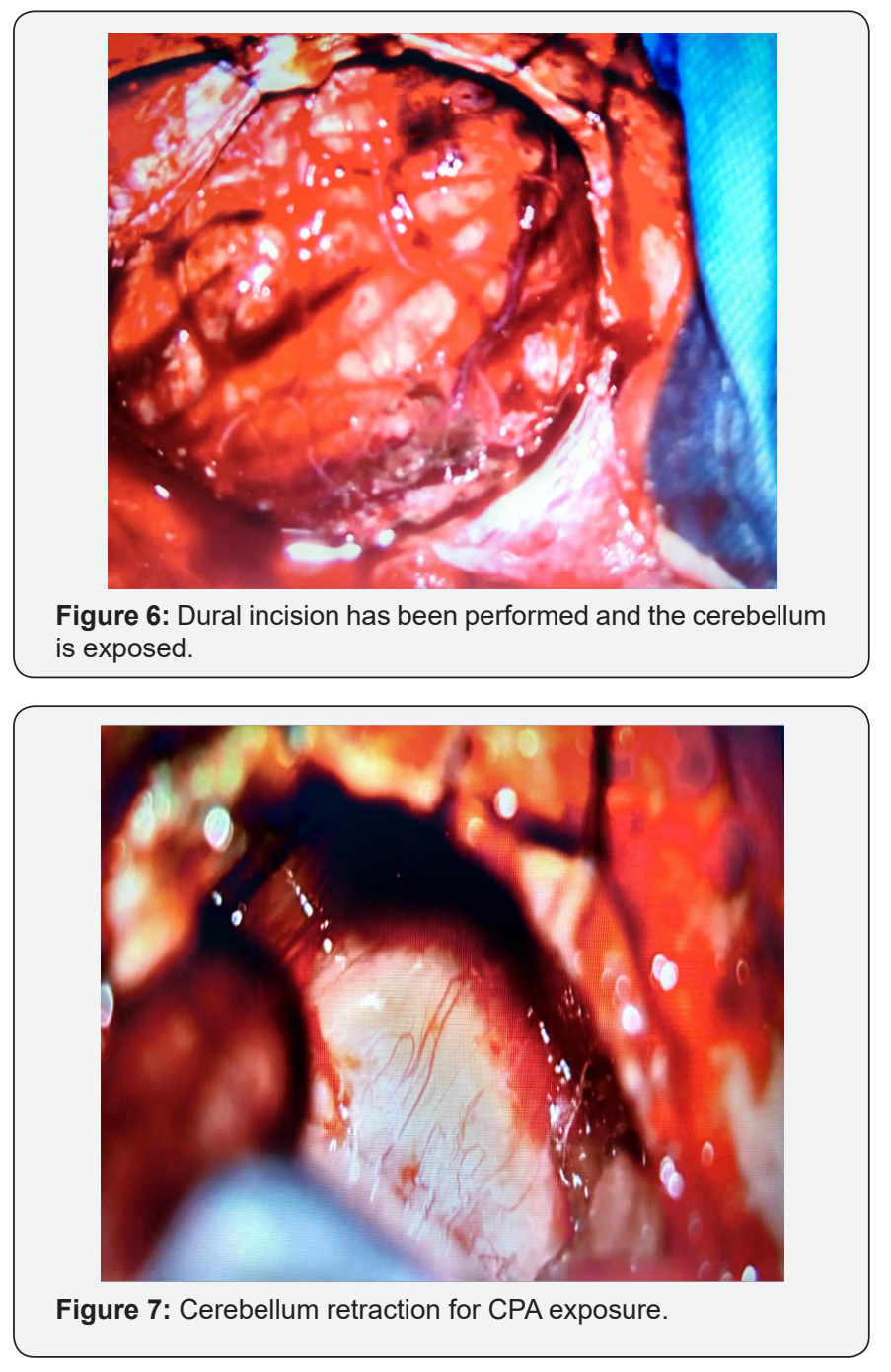

a) Patientpositioning

b) Putting the Mayfield holder to avoid head minor movements

c) Insertion of electrodes on the face (in the tumor side) for facial nerve monitoring

d) Sub occipital incision and flap

e) Drilling and removal of the bone inferior to the transverse sinus and posterior to the sigmoid sinus

f) Dural incision and exposure of the cerebellum very carefully in order not to hit cerebellar vesels

g) Gentle retraction of the cerebellum to reach CPA and the tumor

h) Tumor debulk

i) Dissection of the tumor away from the facial nerve toward the porusacusticus [6]

j) Exposure of the IAC and its drilling (if necessary) to expose and remove the intrameatal portion of

k) the neoplasm

l) Local hemostasis

m) Covering the exposed air cells with bone wax so as to avoid CSF leakage

n) Dural suture

o) Putting the occipital bone removed backin its position (use screws to fix it if needed)

p) Musculoperiosteal flap closure and skin incision suture

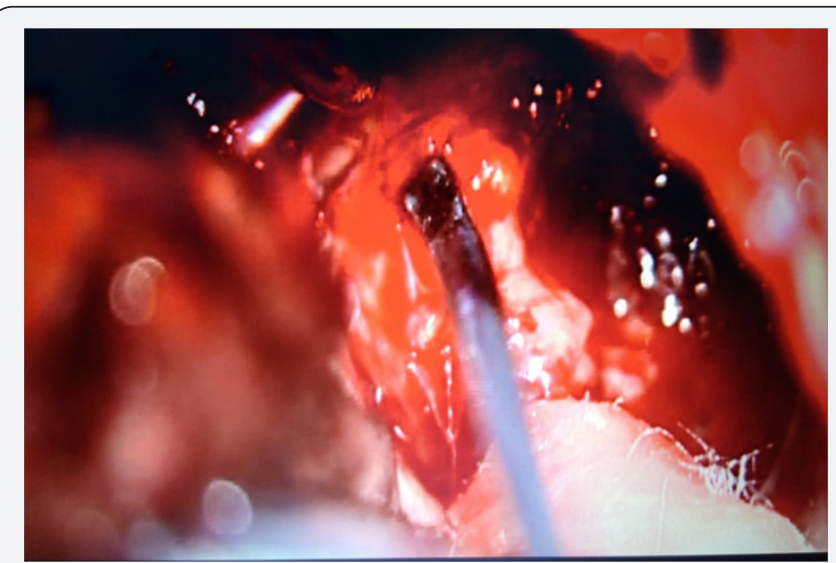

Figure 8: Tumor exposed via retro sigmoid approach (right side of the patient).

q) Face electrodes and Mayfield removal, cleaning and dressing (Figures 8 \& 9).

The middle cranial fossa approach is indicated to remove intracanalicular ANs or tumors that extent up to $1.5 \mathrm{~cm}$ into the CPA. 


\section{Global Journal of Otolaryngology}

The enlarged middle fossa approach allows the resection of even larger neoplasm than the ones mentioned above. This approach is mainly used when there is an attempt to preserve useful hearing on the tumor side [7]. The main disadvantage of this approach is the morbidity that can be caused by the temporal lobe retraction to expose the IAC region and the tumor site. Hence, this approach is not usually indicated for individuals over 65 years or with regular or bad clinical situation. Main surgical steps:

a) Patient positioning

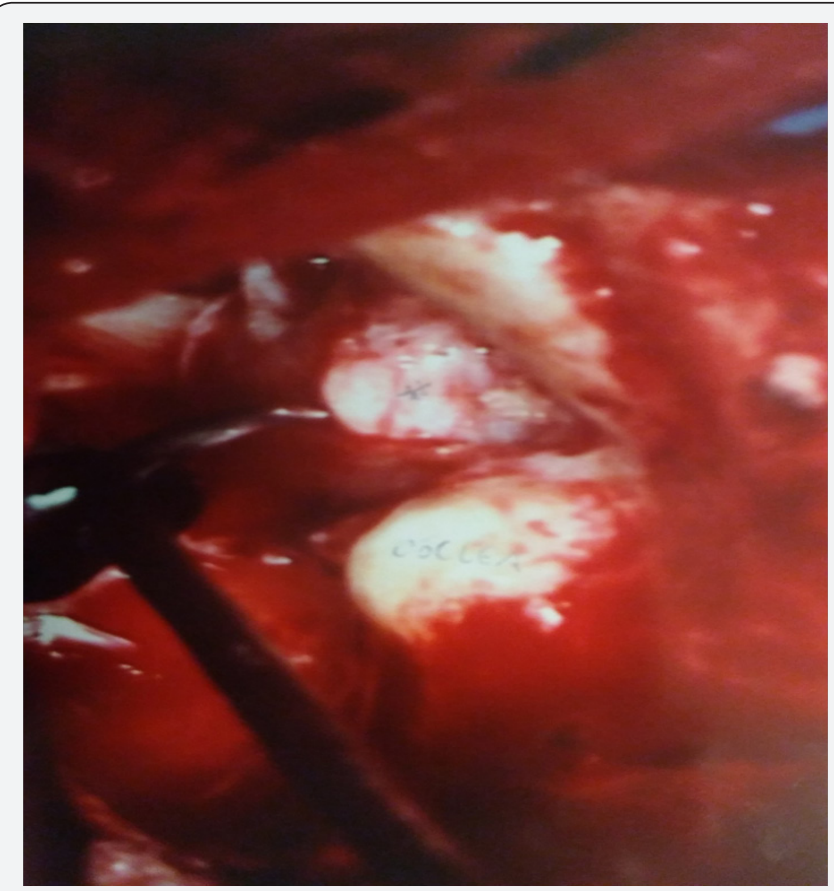

Figure 9: Middle fossa approach - tumor and cochlea are exposed.

b) Insertion of electrodes for ipsilateral facial nerve monitoring

c) The surgeon sits at the head of the table

d) Skin incision is made above of the ear

e) Craniotomy is performed above the floor of the middle cranial fossa

f) The bone flap is removed and kept in saline solution

g) The temporal lobe dura is separated from the edges of the middle fossa

h) The temporal lobe is gently retracted

i) Identification of the actuate eminence, superior semicircular canal and greater superficial petrosal nerve j) Internal auditory canal identification is done. It is located generally in the angle formed

k) arcuate eminence and the greater superficial petrosal nerve

l) The superior face of the IAC is drilled

m) Identification of the superior vestibular nerve and Bill's bar

n) Dura of the IAC opening

o) Identification of the facial nerve

p) Careful tumor dissection

q) Local hemostasis with gelfoam or Surgical

r) Replacement of the bone flap

s) Suture of the temporal is muscle

t) Skin closure

u) Facial nerve electrodes removal

v) Dressing (Figure 9).

w) retrosigmoid, translabyrinthine, or middle fossa approaches and their adaptations or extensions, depending on the tumor size, preoperative hearing status, surgical team experience, and patient preference [8].

\section{References}

1. Netto AATC, Colafêmina JF, Centeno RS (2012) Dural defect repair in translabyrinthineacoustic neuroma surgery ans its implications in cerebrospinal fluid leak occurrence. J NeurolSurg B 73(5): 327-330.

2. Aslan A, Tekdemir I, Elhan A, Tuccar E (1999) Surgical exposure in translabyrinthine approaches - an anatomical study. AurisNasus Larynx 26(3): 237-243.

3. Raza SM, Quiñones Hinojosa A (2011) the extended retro sigmoid approach for neoplastic lesions in the posterior fossa: technique modification. Neurosurg Rev 34(1): 123-129.

4. Di Ieva A, Lee JM, Cusimano MD (2014) Handbook of skull base surgery Sttutgart, New York, USA.

5. Baloh RW, Halmagyi GM (1996) Disorders of the vestibular system. Oxford University Press, New York, USA.

6. Raheia A, Bowers CA, MacDonald JD, Shelton C, Gurgel RK, et al. (2016) Middle fossa approach for vestibular schwannoma:good hearing and facial nerve outcomes with low morbidity. World Neurosurg 92: 37-46.

7. House WF, Shelton C (1992) Middle fossa approach for acoustic tumor removal. OtolaryngolClin North Am 25(2): 347-359.

8. Alzhrani G, Shelton C, Couldwell WT (2017) Middle fossa approach for resection of vestibular schwannoma. ActaNeurochir (Wien) 159(6): 1023-1026. 
This work is licensed under Creative Commons Attribution 4.0 License

DOI: $10.19080 / G J 0.2017 .11 .555824$

\section{Your next submission with Juniper Publishers} will reach you the below assets

- Quality Editorial service

- Swift Peer Review

- Reprints availability

- E-prints Service

- Manuscript Podcast for convenient understanding

- Global attainment for your research

- Manuscript accessibility in different formats ( Pdf, E-pub, Full Text, Audio)

- Unceasing customer service

Track the below URL for one-step submission https://juniperpublishers.com/online-submission.php 